\title{
Atlantis
}

Critical Studies in Gender, Culture \& Social Justice

Études critiques sur le genre, la culture, et la justice

\section{Missing the Point: A Critical Reflection on Operation HONOUR and Reactions to Military Sexual Misconduct by Veterans of the Canadian Armed Forces}

\section{Walter Callaghan}

Volume 41, Number 2, 2020

Gender and the Canadian Armed Forces

URI: https://id.erudit.org/iderudit/1076201ar

DOI: https://doi.org/10.7202/1076201ar

See table of contents

Publisher(s)

Mount Saint Vincent University

ISSN

1715-0698 (digital)

Explore this journal

Cite this article

Callaghan, W. (2020). Missing the Point: A Critical Reflection on Operation HONOUR and Reactions to Military Sexual Misconduct by Veterans of the Canadian Armed Forces. Atlantis, 41(2), 72-87.

https://doi.org/10.7202/1076201ar

\section{Article abstract}

While there has undoubtedly been progress made in regards to the inclusion of women and LGBTQ+ individuals as full members of the Canadian Armed Forces (CAF), it is questionable as to whether the organizational culture has shifted since these efforts were initiated almost thirty years ago. This article argues that resistance to culture change is based in sexist beliefs and attitudes, which are most noticeable in discussions related to Operation HONOUR, the CAF initiative meant to purposefully change military culture in an effort to eliminate sexual misconduct. The article critically reflects on how the CAF has presented results from surveys aimed at examining the beliefs and perceptions of current serving members in regards to sexual misconduct in the military. It argues that the CAF is missing key points of analysis, particularly in failing to identify and analyse the beliefs, attitudes, and behaviours that make up a problematic and misogynistic military culture. To address this, the article presents a taxonomy of sexism to help understand the attitudes of soldiers and veterans. Based on this taxonomy and informed by long-term and ongoing ethnographic research, the article then outlines a spectrum of behavioural archetypes, namely: (1) allyship to victims, (2) willful blindness to the prevalence of and harms caused by military sexual misconduct, and (3) a negative and misogynistic response tied to what has been termed as toxic masculinity. Understanding these behaviours and their embeddedness in veterans' self-perceptions and the military's culture is key to achieving CAF culture change in the context of systemic sexual misconduct.
This document is protected by copyright law. Use of the services of Erudit (including reproduction) is subject to its terms and conditions, which can be viewed online. 


\section{Missing the Point: A Critical Reflection on Operation HONOUR and Reactions to Military Sexual Misconduct by Veterans of the Canadian Armed Forces}

Walter Callaghan is a $\mathrm{PhD}$ candidate (medical anthropology) in the Department of Anthropology at the University of Toronto. His dissertation is tentatively titled "The Subjective Experience of Moral Injuries: Canadian veterans and the meaning they make of psychological distress." He is also a veteran of the Canadian Armed Forces, having served as a commissioned officer from 2001 to 2010.

Abstract: While there has undoubtedly been progress made in regards to the inclusion of women and LGBTQ+ individuals as full members of the Canadian Armed Forces (CAF), it is questionable as to whether the organizational culture has shifted since these efforts were initiated almost thirty years ago. This article argues that resistance to culture change is based in sexist beliefs and attitudes, which are most noticeable in discussions related to Operation HONOUR, the CAF initiative meant to purposefully change military culture in an effort to eliminate sexual misconduct. The article critically reflects on how the CAF has presented results from surveys aimed at examining the beliefs and perceptions of current serving members in regards to sexual misconduct in the military. It argues that the CAF is missing key points of analysis, particularly in failing to identify and analyse the beliefs, attitudes, and behaviours that make up a problematic and misogynistic military culture. To address this, the article presents a taxonomy of sexism to help understand the attitudes of soldiers and veterans. Based on this taxonomy and informed by longterm and ongoing ethnographic research, the article then outlines a spectrum of behavioural archetypes, namely: (1) allyship to victims; (2) wilful blindness to the prevalence of and harms caused by military sexual misconduct; and (3) a negative and misogynistic response tied to what has been termed as toxic masculinity. Understanding these behaviours and their embeddedness in veterans' self-perceptions and the military's culture is key to achieving CAF culture change in the context of systemic sexual misconduct.

Keywords: Canadian Armed Forces, ethnography, military culture, military masculinity, sexism, sexual misconduct 
$\mathrm{T}$ he last century (and a bit) has seen remarkable gains in terms of women serving in the Canadian military, from being limited to roles as nursing sisters to being able to serve in any position within the military. ${ }^{1}$ But this access and integration is overshadowed by an organizational culture that has been described by the Deschamps Report as highly sexualized and hypermasculine (Deschamps 2015). The Deschamps Report was the product of an external review of the Canadian Armed Forces (CAF), commissioned by General Lawson, then Chief of Defence Staff, in response to media reports on incidents of sexual harassment and sexual assault within the CAF. Operation HONOUR, the official response of the CAF to the findings of the Deschamps Report, has as one of its fundamental objectives to change the hypermasculine culture of the CAF.

This article explores the culture of the CAF by examining the social attitudes and related behaviours of serving members and veterans in response to sexual misconduct in the CAF, and in response to initiatives like Operation HONOUR. Sexual misconduct, as defined by the CAF, ranges from sexual harassment and gender discrimination to sexual assault. ${ }^{2}$ In an effort to understand what is happening in the CAF in terms of sexual misconduct, the implementation of Operation HONOUR, and the potential for culture change, this article first examines several iterations of the Survey on Sexual Misconduct in the Canadian Armed Forces (SSMCAF), a survey administered to serving members of the CAF by Statistics Canada (Cotter 2016, 2019). The findings of these surveys have been largely limited to internal reports in the Department of National Defence, though some results have been made publicly available by Statistics Canada.

In this article, I discuss how the survey results have been disseminated by the CAF, using conference presentations I attended as an example. The CAF has publicly framed the survey findings by focusing on (1) the extent to which members of the CAF know about Operation HONOUR; and (2) if they believe that there is a problem with sexual misconduct within the CAF. By focusing on these two areas, I argue that the CAF continues to "miss the point" on how to create culture change because they do not address the values and their associated behaviours that underpin the prevalence of sexual misconduct within the CAF. History seems to be repeating itself, as the Deschamps Report called out the CAF for having a similarly narrow, misleading, and erroneous focus in how it responded to and represented findings from earlier surveys on harassment, diversity, and employment equity (Deschamps 2015). ${ }^{3}$

After identifying what is missing from the CAF analysis, I introduce an extant taxonomy of sexism developed by Lauren Young and Margaret Nauta (2013) to help make sense of military members' attitudes towards sexual harassment and assault. This taxonomy consists of old-fashioned sexism, modern sexism, hostile sexism, and benevolent sexism. While elements of this taxonomy have been around since at least the 1990s, they have not been picked up and applied, particularly in military settings where this taxonomy can be of use in understanding the value systems that underpin military culture and how that culture impacts and creates space for military sexual misconduct and trauma to occur.

Finally, I use Young and Nauta's taxonomy to identify a spectrum of behaviour I have observed during my ethnographic research among veterans in response to the findings of the Deschamps Report and Operation HONOUR: (1) potential allyship with victims; (2) wilful blindness to the prevalence of and harms caused by military sexual misconduct; and (3) a negative and misogynistic response tied to what has been termed as toxic masculinity. These three moments or archetypes are not static but contextually fluid and dependent on the social relations of the actor, the situation, and the victim, as will be explained.

The findings and discussion in the third section of the article are based on long-term, ongoing ethnographic research I am conducting with veterans of the CAF as part of a dissertation project in medical anthropology that examines the subjective experiences of psychological distress and moral injuries. ${ }^{4}$ This ethnographic research has included intensive participatory observation 
in multiple field-sites, involving both in-person and virtual/online settings. During interactions with veterans in this way, by attending protests, meet-and-greets, hearings at government panels, and a wide variety of other events, the focus has been on how veterans interact with each other in a natural setting, observing what topics are discussed and how they are discussed, with the discussions being led completely by the veterans rather than by an external research protocol being applied to them. Similarly, in observing interactions between veterans in online/virtual social networks, such as Facebook groups, I am able to track and capture how veterans are presenting themselves and what they think about or how they react to certain situations. Many of the quotes used in the third section are based on interactions that occurred in several social media forums in reaction to reports in the news media about the Government of Canada settling a class-action lawsuit filed by victims of sexual misconduct in the CAF (Brewster 2019; Tasker 2018; Tunney 2019).

Readers may wonder why this ethnographic research was conducted with veterans and not with current serving members of the CAF. The simple answer is that it was easier to obtain access to veterans because research access to serving members of the CAF is tightly controlled by the Department of National Defence. Complicated by levels of bureaucratic control, active and intensive ethnographic research with current serving members of the military was not feasible. However, being a veteran of the CAF myself, and an active advocate for veterans, I find myself intimately involved in the wider veterans' community in Canada (and abroad), and well-situated to ask some of the questions that led to the development of the ideas in this article. Many of the veterans involved in this research have remarked on how they find themselves in what I would call a liminal place between the military and civilian worlds. The values and behaviours developed during their time in the military still affect their perceptions and behaviour while trying to live new lives in the civilian world. Given the role and impact of the intensive indoctrination that occurs during basic training, and how the values and beliefs introduced during that indoctrination are reinforced throughout one's life in what is akin to a total institu- tion (Foucault 1975; Goffman 1961), veterans can provide a window into military life and culture. I therefore use insights I gained from my ethnographic research with veterans to shed light on the challenges the military is experiencing in addressing sexual misconduct, specifically those related to the underlying culture of the institution.

Readers will note that in the third section, where the voices of these veterans are presented, there are no markers indicating trade or rank of the veterans themselves. I have done this on purpose in an attempt to preclude readers from making assumptions about the prevalence of these behaviours in the different branches of the military. Without further research and analysis, it would be erroneous to make any claims that the different behaviours presented are more predominant in certain military elements or trades, or at certain rank-levels. In regard to when these veterans served and were released from the CAF, this information is not presented because there was remarkable similarity in the values and behaviours observed with these veterans despite a large temporal range in when their release from the CAF occurred, with some individuals having released from the CAF in the 1990s and others only being in the process of release at the time of ethnographic engagement. In summary, based on long-term and ongoing interaction with these veterans, I have identified problematic behaviours among the veteran community that need to be acknowledged and addressed if the intended culture change underpinning Operation HONOUR is to have any real chance of success.

While there has been some insightful research published on the intersection of gender and military culture within the CAF, most of this work has focused on government policy and at an organizational level (e.g., Chapman and Eichler 2014; Davis 2009, 2019; Eichler 2013, 2016; McCristall \& Baggaley 2019; Okros \& Scott 2015; Taber 2018, 2020). Certainly valuable in its own right, this research has not been able to capture and describe the values, perceptions, and behaviours of serving members and veterans on an individual level, especially those who resist the call for culture change put forward with Operation HON- 
OUR. My article contributes to ongoing feminist-informed Canadian research on the military and its gendered culture by filling in this gap, particularly in providing two conceptual frameworks that will assist in targeting research and policy development efforts in effecting culture change in the CAF: (1) a taxonomy of sexism for analyzing the values and beliefs associated with gender and military sexual misconduct; and (2) a spectrum of archetypes that capture the behaviours that are based on those values and beliefs. I believe that a better understanding of how sexism operates within the military and manifests in particular behaviours among service members and veterans is a necessary first step in better understanding the prevalence of sexual misconduct, responses to sexual misconduct by military members, and how to bring about effective change.

\section{The SSMCAF: Problematic Discourse and Missing the Point of Culture Change}

In order to understand and identify any changes within the culture of the CAF, several studies have been conducted to create a baseline of knowledge in terms of the prevalence of sexual misconduct within the CAF, and the beliefs and attitudes that serving members hold towards sexual misconduct. This includes the 2016 Survey on Sexual Misconduct in the Canadian Armed Forces (SSMCAF) (Cotter 2016) and the subsequent repeat of that survey in 2018 (Burczycka 2019; Cotter 2019). Data from the 2016 and 2018 iterations of the SSMCAF (Dursun 2019), along with comparison data from the application of the SSMCAF to recruit populations of the CAF (LeBlanc 2019; LeBlanc et al. 2018, 2019), were presented at the 2019

\begin{tabular}{|l|l|r|r|r|r|}
\hline \multicolumn{6}{|c|}{ Selected Results from Survey on Sexual Misconduct in the Canadian Armed Forces } \\
(SSMCAF)
\end{tabular}


Forum of the Canadian Institute for Military and Veteran Health Research (CIMVHR), a key annual event that brings together researchers and clinicians from within and outside the military working on military and veteran health issues.

When survey data on the prevalence of experienced and/or witnessed sexual misconduct were presented by representatives of the Department of National Defence, the focus was consistently placed on how many respondents knew about Operation HONOUR and how well the respondents thought the CAF was doing in addressing issues of sexual misconduct (Dursun 2019; LeBlanc 2019). These presentations were received with some dissatisfaction by audience members who made their concerns known over what was perceived to be an attempt at "sugar-coating" the interpretation of data that clearly indicated the presence of significant issues concerning not just the prevalence of sexual misconduct within the CAF but also the perceptions of and attitudes towards sexual misconduct that were captured in each iteration of the SSMCAF. In short, these presentations and the response of audience members suggested to me that while the SSMCAF had captured some significant and important data, the purpose of these surveys had been missed altogether.

In considering sexual misconduct, the SSMCAF included definitions of sexual assault, sexualized behaviour, and sexual discrimination, and captured the incidence rates of each of these over the previous 12 months, with separate accounting for both having witnessed such incidents and also having personally experienced an incident (Burczycka 2019; Cotter 2016, 2019). For the SSMCAF (Cotter 2019), sexual assault includes "sexual attack, unwanted sexual touching, and sexual activity where unable to consent"; sexualized behaviours include inappropriate verbal or non-verbal sexual communication, sexually explicit materials, and physical contact or suggested sexual relations; and finally, sexual discrimination encompasses discrimination on the basis of sex, sexual orientation or gender identity. In terms of sexual misconduct, the 2018 SSMCAF noted that $1.6 \%$ of Regular Force members ( $4.3 \%$ females, $1.1 \%$ males) of the CAF had experi- enced sexual assault during the previous 12 months (Cotter 2019) which was not statistically different from the incident rate noted in the 2016 SSMCAF (1.7\% overall: $4.8 \%$ females, $1.2 \%$ males (Cotter 2016)). The 2018 SSMCAF also found that $70 \%$ of Regular Force members (74.7\% females, 69.8\% males, $76.2 \%$ gender diverse) had witnessed or experienced an act of sexualized behaviour or discrimination (Cotter 2019), which was a notable decrease from the $80 \%$ of members ( $83.8 \%$ females, $79.4 \%$ males) who had endorsed having witnessed or experienced such acts in the 2016 iteration of the SSMCAF (Cotter 2016) but which remains disturbingly high and raises questions about the effectiveness of the implementation of Operation HONOUR.

Alarmingly, the data from the recruit SSMCAF indicated that $91.8 \%$ of private recruits $(94.3 \%$ females, 90.5\% males (LeBlanc et al. 2018)) and $86.4 \%$ of officer cadets (94.4\% females, $84.2 \%$ males (LeBlanc et al. 2019)) had witnessed or experienced some form of sexualized behaviour or discrimination during the 12 weeks of their basic military qualification training, with $5.6 \%$ of females and $1.5 \%$ of males reporting having experienced a sexual assault during their recruit training (LeBlanc et al. 2018). An important limitation of the recruit SSMCAF is that it was only administered to individuals who successfully completed BMQ (Basic Military Qualification, for private recruits) or BMOQ (Basic Military Officer Qualification, for officer cadets). It is not stated what the completion rates were for these courses or, potentially more importantly, why individuals did not complete these courses. 5

When these alarming numbers were presented at CIMVHR 2019 (Dursun 2019; LeBlanc 2019), more effort seemed to be placed on highlighting data on serving members' knowledge of Operation HONOUR and perceptions of its effectiveness, noting that almost every respondent acknowledged awareness of the program, with $93 \%$ of males and $92 \%$ of females providing a positive endorsement ("agree" or "somewhat agree") of the survey statement "the Canadian Armed Forces currently works hard to create a workplace that prevents inappropriate sexual behaviour" (Cotter 
2019; Dursun 2019). These responses led to the claim that most respondents believed that Operation HONOUR was effective (Dursun 2019). However, when the data is examined more closely, this positive endorsement drops for those who had experienced sexual assault ( $83 \%$ males, $77 \%$ females) or sexualized behaviour/discrimination (89\% males, $76 \%$ females) (Cotter 2019). Perhaps more importantly, the survey statement "Inappropriate sexual behaviour is a problem in the Canadian Armed Forces" was positively endorsed overall by $40 \%$ of males and $53 \%$ of females, and for $38 \%$ of males and $64 \%$ of females who had experienced sexualized behaviour/discrimination and $55 \%$ of males and $76 \%$ of females who had experienced a sexual assault (Cotter 2019). Instead of attempting to present only the more positive perception that the CAF is addressing issues of sexualized behaviour as was done at CIMVHR 2019 (Dursun 2019), the positive endorsement of both statements needs to be taken together and should be read as: there continues to be a problem with inappropriate sexualized behaviour in the CAF and serving members believe that the CAF is attempting to fix this problem.

The 2018 version of the SSMCAF also included questions regarding bystander interventions (Cotter 2019), but such interventions were found to have occurred at fairly low rates and with women being significantly more likely to take some form of intervening action than men. ${ }^{6}$ In cases of inappropriate verbal or nonverbal communication (sexual jokes, unwanted sexual attention, inappropriate sexual comments, and inappropriate discussion about sex life), $49 \%$ of women versus $43 \%$ of men took action in at least one instance. This was similar for incidents involving sexually explicit materials, physical contact, or suggested sexual relations, where $50 \%$ of women versus $38 \%$ of men took action in at least one instance. In cases of witnessing discrimination based on sex, sexual orientation, or gender identity, action was taken in at least one instance by $59 \%$ of women and $43 \%$ of men. The predominant action taken was talking to the person responsible for the behaviour; formal reporting of the incident occurred far less often with only $33 \%$ of women reporting the second category of behaviour (sexually explicit materials, physical contact, or suggested sexual relations). It should be noted that the list of possible actions taken were not mutually exclusive, and it is more than likely that individuals both spoke to the person responsible for the behaviour and officially reported the incident. However, the low level of reporting is problematic, as are the reasons for not reporting incidents (discussed below). This in turn may be one reason why the Department of National Defence has introduced a duty-to-report (Department of National Defence 2019).

The reasons for not intervening or taking some kind of action are particularly troubling, especially in the case of inappropriate verbal or non-verbal communication where $80 \%$ of men and $70 \%$ of women did not take any action because they did not believe that any action was needed or that they did not think the behaviour was serious enough to warrant action on their part (Cotter 2019). This was a significantly more common reason for not acting than fear of negative personal consequences (endorsed by $5 \%$ of men and $12 \%$ of women), fear of negative personal consequences for those targeted (3\% of men, $7 \%$ of women), or because the perpetrator was of a higher rank ( $6 \%$ of men, $10 \%$ of women), though it should be noted that the reasons for not taking action or intervening in some way were also not mutually exclusive and multiple reasons could be at play in any given situation. Unfortunately, the SSMCAF did not delve further into why respondents did not believe that any action was needed or that the incident being witnessed was not serious enough to warrant action.

\section{Taxonomy of Sexism: A Conceptual Frame- work to Describe Beliefs and Values}

This section introduces a conceptual framework of the different forms of sexism developed by Young and Nauta (2013) to help elucidate the broader culture within which sexual misconduct of all forms occurs, from sexual assault to sexual harassment and gender discrimination. Such a framework can help us understand why individuals may have believed that no action was needed in the face of witnessing an incident of sexual harassment or assault, or that an observed incident of sexual misconduct was not serious enough to 
warrant action. This taxonomy was included and applied to a CAF report detailing conceptual issues regarding leadership and implicit bias within the CAF (Kocum et al. 2017) but does not seem to be included or acted upon in the CAF's discourse and analysis of the SSMCAF data described above. I believe that this framework would also be useful to the CAF in interpreting the findings of past and future iterations of the SSMCAF.

Young and Nauta's (2013) taxonomy includes several forms of sexism in relation to attitudes towards women in the military, namely: (1) old-fashioned sexism which holds that women are inferior and have no place in the military or, in more extreme forms, any role outside of the home in general; (2) modern sexism, which denies the existence of sex discrimination and holds a toxic response towards social policies aimed at improving sexual and gender equality and equity; (3) hostile sexism, or outright antipathy and anger towards women, particularly in relation to sexual access; and (4) benevolent sexism, exemplified by ostensibly prosocial behaviours that become sexist as a result of problematic perceptions of women as innocent and needing protection. While initially developed to describe the views held about female members of the military, and women in general, this taxonomy is also useful for understanding the underlying views held in relation to gender diverse servicemembers. These forms of sexism overlap with each other, with hostile sexism being a more aggressive representation of elements of old-fashioned and modern sexism, and benevolent sexism exhibiting more prosocial and subdued elements derived from both old-fashioned and modern sexism.

Old-fashioned sexism relies on sociobiological myths of the inferiority of women and other non-hetero-male genders and sexualities and is strongly connected to, and influenced by, hypermasculine tropes of the warrior as the ideal embodiment of masculinity. This idea of the masculine warrior underpins the sexist perception that women do not belong in the military. In this form of sexism, victim-blaming is rampant, particularly in forms that blame the victim's presence for the ensuing misconduct, inferring that it would not have happened if they had not been there in the first place, and that the mere presence of a female created an environment or situation where males were not able to restrain themselves. Old-fashioned sexism is reflected in the arguments put forward by the Canadian leadership in opposition to women's full integration into the combat arms during the 1980s - that the mere presence of women would be harmful to operational effectiveness and unit cohesion (Davis 2020; Eichler 2013). In terms of male victims, this can take the form of inferring that the victims are not "man enough" to be in the military, especially in the context of sexual misconduct connected to hazing rituals.

Modern sexism, on the other hand, acknowledges the inappropriateness of the values held by old-fashioned sexism, but is marked by an ideology purporting that: (1) things have changed, and that discrimination and harassment no longer exist; and (2) incidents of claimed misconduct, harassment, or discrimination are exaggerated, sensationalized, or fabricated. This form of sexism is often characterized by resentment of the integration of women and LGBTQ+ individuals into the CAF and the accompanying change of culture. Lucie Kocum et al. (2017) provide a detailed discussion of the differences between old-fashioned and modern/contemporary sexism, particularly in regard to the change from overt to covert/subtle acts of discrimination and misogyny, including differentiating between covert and subtle forms of harmful behaviour and their underlying attitudes. Modern sexism in the military manifests, for example, in that while women are now technically permitted into all roles and trades within the CAF, the perpetuation of a masculine ideal continues to limit non-male participation and representation within the military (Davis 2020; Eichler 2013).

Hostile sexism is related to the behavioural enactment of misogynistic values represented by both old-fashioned and modern sexism, and while the term might instill a belief that such acts are inherently overt in nature, both Young and Nauta (2013) and Kocum et al. (2017) illustrate how hostile sexism can also be enacted covertly or subtly. The key indicator of hostile sexism is the presence of antipathy, or even overt hatred, toward women or LGBTQ+, or even male vic- 
tims. The Deschamps Report noted some aspects of hostile sexism in the military, expressed in the normalized sexualized and hypermasculine culture (Deschamps 2015).

Benevolent sexism is perhaps the form of sexism that will be the most problematic for Operation HONOUR to address, as it is intimately linked to the socially constructed identity of the Canadian Armed Forces member as protector and hero, and conceives of anyone who does not exhibit, demonstrate, or perform the masculinity associated with this ideal as people needing protection. Kocum et al. (2017) argue that "although seemingly positive, these 'protective' views of women are further damaging to women's advancement in the workforce, as they restrict women's employment opportunities and ultimately condone sexism by construing it as inevitable" (23).

The taxonomy of sexist beliefs described by Young and Nauta (2013) provides us with a good starting point to understand the performative behaviour and masculinized military culture of veterans and serving members of the CAF - and why individuals behave the way they do towards victims of sexual misconduct. However, the taxonomy itself does not describe or capture what that behaviour is. Therefore, in the following section of this article I provide examples of behaviours I have observed during fieldwork to elaborate on how the taxonomy of sexism manifests.

\section{Allyship, Wilful Blindness, and Toxic Mas- culinity: A Continuum of Performative Be- haviour}

Building on Young and Nauta's (2013) taxonomy, I have found three archetypes of performative behaviour in response to Operation HONOUR through my ethnographic research with veterans: (1) allyship; (2) wilful blindness; and (3) toxic masculinity. ${ }^{7}$ These archetypes exist along a continuum, and the positionality of any given individual on that continuum is not static but highly mobile and context dependent. This fluidity becomes apparent when issues of female, male, or LGBTQ+ victims of sexual misconduct are being considered. For instance, an individual could conceiv- ably act as an ally towards female victims of sexual assault but be wilfully blind to the prevalence and effects of sexual harassment; or they could be supportive of female victims of all forms of sexual misconduct but have hostile and toxic responses to male or gender-diverse victims.

Allyship is connected to positive and supportive bystander behaviour, including the open acknowledgement that a problem exists within the culture of the CAF as well as willingly acting to intervene and put a stop to acts of sexual misconduct and discrimination. While perhaps still the rarest of the archetypes observed within the veteran community, there are individuals who are willing to step forward and risk social exclusion by taking action when instances of harassment or discrimination, including hostile acts of both old-fashioned and modern sexism, are committed by other members of the veterans' community. Some of these individuals profess to have been willing to act as allies for long periods of time, even prior to joining the military, while others have found themselves drawn to become allies in part as a result of the psychological distress that they have themselves endured. Interestingly, the most outspoken and active of "allies" that I have encountered are individuals who have trauma histories unrelated to either combat or military sexual trauma. As Charles, a male veteran, succinctly puts it:

Yeah, I'm hurting. I think it makes me more open to the pain that other people are experiencing, and who am I to make any judgement over why they're hurting. They're hurting, that's enough for me. But when I see other male veterans dismiss that pain or call it fake or put it down as not being as serious as theirs because they were over in the sandbox, especially when what they're dismissing is pain caused by the sexism that we were all a part of ... that pisses me off. But I can do something about that now. I can call these assholes out for what they are. I can't change what happened, but I can help put a stop to it continuing.

This veteran, like many other veterans I encountered who are actively engaged in challenging any incident of sexism or sexual misconduct, sees his interventions 
as part of his own healing, as being both a process and result of post-traumatic growth. He believes that he has become more aware and sensitive to the experiences of others and finds himself unable to step aside and remain silent, acknowledging that he had failed to act in the past and feels a degree of guilt over his past inaction. He frequently wonders whether his lack of action may have led to a perpetrator committing sexual assault at some point. Many of these veterans acknowledge that their past behaviour while they were still serving in the CAF was problematic, admitting to and trying to make amends for their own personal participation in what they perceive to be a toxic environment and culture.

However, there is a fine line between allyship and benevolent sexism, a line that is not always clearly delineated and can be difficult to identify, again largely because of the "protector" role taken on by many/most members of the military. This line is difficult to manage, particularly for veterans who are newly engaged with this type of activism while also balancing their own issues of emotion regulation connected to posttraumatic stress disorder, most especially when that PTSD is derived from a moral injury. ${ }^{8}$ The impulse to act without paying attention to the desires or wishes of victims or recipients of sexist remarks or behaviour creates a situation where the would-be ally is performing an act of benevolent sexism in that there is little or no opportunity given to the victim to determine on their own what they wish to be done in response to sexual misconduct, in effect denying them agency and autonomy. Paying attention to the needs or wishes of would-be victims takes time, and most of the "allies" who have shared their experiences throughout this research project have acknowledged that they have struggled with balancing this with their own personal drive to act and react to situations or behaviours that they perceive as being extremely problematic and in need of challenge.

On the other side of the spectrum are those veterans who perform toxic masculinity - those who openly and unrepentantly engage in acts of hostile sexism, both of the old-fashioned and modern/contemporary forms, though the former is definitely more noticeable in its violently sexual objectification of women and dehumanization of LGBTQ+ individuals. Endorsement and use of rape-myths is prevalent amongst these veterans, and challenges towards such behaviour are frequently met with open hostility and derision. For example, Ryan, a male veteran, easily and openly remarked during a discussion about the Deschamps Report and the prevalence of sexual misconduct noted in that report: "If one cannot handle this lifestyle don't take on this kind of occupation and then complain about it." Ryan went on to endorse a position clearly holding views of old-fashioned sexism where, in his mind, even if the victims were actually sexually assaulted, they were to blame for being where they should not have been in the first place, that they brought the assault on by being "teases" simply by virtue of being female, and also endorsing the rape-myth that men have "undeniable sexual urges."

Just as common as the hostile sexism put forward by Ryan was the attempt to frame accusations of sexual assault or sexual misconduct as being connected to revenge, as put forward by James, another male veteran: "How about the offended be required to prove intent as well-most of these issues are BS for the most part and based on revenge, in my opinion." This position, that the accusations are fabricated or exaggerated, was also endorsed by a handful of female veterans, such as Lindsay, who became quite agitated and aggressive during a similar discussion about sexual misconduct in the military: "I also witnessed that there were often two sides to a story that never got told! Hmmm?"

Each of these encounters with veterans who were enacting hostile sexism in response to questions and discussions centered on sexual misconduct in the military created ethical dilemmas for me about whether and how to proceed with engaging them as participants in the larger ethnographic research project. These individuals were prone to aggressively asserting that asking any questions about this topic was "just part of a femnazi conspiracy to make our military useless" (Lindsay) or attempting to defend their positions on the basis of an assumed inherent biological difference between "real men and those who need to stay home and do what they're told" (Ryan). 
Taking up the middle ground between these two archetypical end-points on a spectrum of behaviour are those who I label as being wilfully blind. This position itself, as with the allyship and toxic masculinity archetypes, should be understood as a continuum and one where the individual is not static but shifts based on the context, perhaps more so than the other two archetypes discussed above. While the veterans whose behaviour I identify as being wilfully blind admit it is possible that sexual misconduct exists and occurs, they have a hard time acknowledging the scale of the problem because they do not recall ever having witnessed an incident. As Mark explained:

I have no doubt that this has happened. What's your point? The CAF is representative of Canadian society and as such has the same issues. My only point is that I have never seen or witnessed or heard of sexual harassment or assault in the places that I served while I was there. I find this weird because I was a support trade and a support officer my entire 35-year career where we would have had the largest number of female service women (sic). It should be noted that there is no statute of limitations on sexual assault. If there is anyone out there that has been sexually assaulted, they should report it. This type of behaviour is totally unacceptable and illegal.

For Mark, there is no question that sexual misconduct occurs, and that it should be punished, but the question for him is how prevalent it is, and how serious it is. There is a degree of modern/contemporary sexism at play in Mark's thinking, in that he struggles to accept that the problem is as common or prevalent as the SSMCAF surveys (presented earlier in this article) and the Deschamps Report indicate. Positions like Mark's, at times, tend to cross over into the realm of toxic masculinity. While not openly challenging that accusations are fabricated, he does admit to wondering how often an incident might just be the result of a misunderstanding and miscommunication between males and females. He attempted to defend his position further by admitting that while such incidents might cause harm to someone, such misunderstandings or miscommunication should not end someone's career. There is a clear cognitive dissonance exhibited here as to the extent of harm that can be caused by prolonged exposure to a toxic masculine environment where sexualized behaviour is permitted to exist because, as similar-thinking veterans frequently responded upon being challenged, "it's just harmless fun." In light of the rates of witnessing that were found in the SSMCAF surveys, it is difficult to fathom how someone could spend multiple decades in the CAF and not witness at least one instance of sexual misconduct unless the individual is purposefully turning a blind eye. Further, as I experienced when speaking with Mark, challenging such a position with data like that from the SSMCAF can lead to hostility, curtailing opportunities to delve further into how and why they think and behave in these ways.

In my ethnographic research, I have observed that acts of wilful blindness often go hand-in-hand with a suspicion towards the motives of Operation HONOUR. This suspicion seems to be based in cynicism connected to modern or contemporary sexism that holds to the position that gender integration was an endpoint wherein "equality" has been achieved and further work is neither needed nor welcome. This is demonstrated by another of James' comments: "Well it will be abused just like everything else in the past 10 years, if we reinstall common sense into this world maybe things would work out." For James, the entire purpose of Operation HONOUR is believed to be one intended to force military members to accept things that do not exist; Operation HONOUR opens the door to what he perceives as being revenge-motivated persecution of men rather than an attempt to change a toxic culture and create a more welcoming and hospitable work environment. This form of wilful blindness, and the belief that these changes are harmful rather than helpful, is not unique to male veterans. It has been exhibited by female veterans as well, demonstrating the difficulty in changing a culture based on aggressive masculinity, such as this response from Mary:

That's just great. So the forces can't use force, can't touch each other, can't swear or say racial slurs. Sounds like they're being prepared for war alright. My unit made lots of inappropriate jokes and swore amongst ourselves all the time. 
It's what brought us together and bonded us to this day. And pushing and shoving was something we did that was fun. All these rules make no sense to me.

Resonating with the SSMCAF findings that bystander inaction was frequently connected to a belief that the witnessed behaviour was not serious enough to warrant intervention, Mary has a difficult time believing that there was any harm caused by the behaviour that she witnessed and participated in. For her, this behaviour was normal and expected; it helped build unit cohesion fundamental to creating an effective fighting force, and any attempt to change this culture was, and is, detrimental rather than beneficial.

However, some veterans who have struggled with acknowledging the prevalence of sexual misconduct in the CAF are open to being corrected, and while not actively engaged in allyship, there are some who have shown remorse and shock when I have provided them with a thorough description and definition of what constitutes sexual misconduct, as well as information on how existing for prolonged periods in a toxic environment affects the psychological well-being of exposed persons. While not always transitioning fully to the behaviour labelled as allyship, this willingness to accept and acknowledge that there are problems does provide hope that things can change, even if most of the veterans going through this transition tend to remain uncertain about whether Operation HONOUR is the right path to take. Given that the most common reason for bystander inaction listed in the SSMCAF surveys was not believing that the situation was serious enough, but at the same time noting high levels of witnessing sexual misconduct, sheds some light on the cultural norms and beliefs that are at play but which were not captured by the SSMCAF surveys. This demonstrated ability by some veterans to recognize wrongdoing and shift one's stance towards sexual misconduct also provides some hope that Operation HONOUR can have a positive impact through education, even though we are not seeing clear evidence of such culture change as of yet. Perhaps new iterations of the SSMCAF will find that there has been change since the 2018 iterations.

\section{Conclusion}

While the research presented in this article has focused on CAF veterans rather than currently serving members, the positions and views put forward can and should be viewed as glimpses into the culture of the CAF and provide insights that can help guide Operation HONOUR. Many of these veterans still strongly identify with the CAF. While all of these individuals have, or are in the process of being, released from the military, I have encountered the types of views and behaviours presented in this article repeatedly over the course of my near-decade-long ethnographic research.

For an organization like the CAF, culture change is not going to be easy or quick, but for initiatives like Operation HONOUR to be successful there needs to be more knowledge about, and acknowledgement of, what the underlying culture actually is, especially at the individual level among those who resist or reject the call for change inherent in Operation HONOUR. While the SSMCAF surveys provide insight into the prevalence of certain types of thinking, such as the commonly held belief that witnessed acts of sexual misconduct are not serious enough to warrant intervention, they fail to go in-depth and provide a thorough understanding of what beliefs and values underpin these reasons for inaction. Recognizing that there is only so much that can be accomplished with close-ended surveys such as the SSMCAF points to a clear need for more extensive research aimed at delving into the why and how of the behaviours and beliefs that I found in the course of my research. This failure to identify and examine the underlying values and beliefs held by members of the CAF, and the associated behaviours, is where I believe the CAF has missed the point in its effort to create culture change. This article has provided a taxonomy of sexism and related archetypes of behaviour to help enable a better understanding of where the culture of the CAF currently lies and where to focus efforts in changing that culture in positive ways. 


\section{Endnotes}

1. For a critical analysis of how gender inclusion has been handled in the Canadian Armed Forces, see Davis (2020).

2. In 2019, the Canadian Department of National Defence finally released a conceptualization of sexual misconduct as being a spectrum of behaviour, acknowledging that all forms of sexual misconduct, from sexual harassment and gender discrimination to sexual assault, are problematic and can cause harm: https://www.canada.ca/en/department-national-defence/ services/benefits-military/conflict-misconduct/operation-honour/training-educational-materials/spectrumsexual-misconduct.html.

3. Deschamps Report (2015, 8): "Following the release in 2013 of the results of the 2012 Harassment and Diversity and Employment Equity surveys, the CDS circulated a message highlighting what he viewed as positive trends in the prevalence of harassment, including sexual harassment in the organization: 'The surveys present a number of positive results and trends: a large majority of our members stated that they had not experienced any of the four forms of harassment in the CAF in the past 12 months; the majority of our members do not perceive the CAF as a whole, as well as the leadership, to be tolerant of harassment; and the majority of Regular Force members believe that the CAF climate is positive and accepting of diversity.'”

4. The ethnographic research that this article is drawn from is a larger doctoral project in medical anthropology focused on how veterans make meaning of the psychological distress that they experience, with a focus on the concept of the moral injury. This larger doctoral project and its ethnographic methods received approval from the Office of Research Ethics at the University of Toronto. The names of all veterans quoted in this article are pseudonyms.

5. This is potentially important as there is the possibility that individuals who dropped out of training as a consequence of having been victimized while on course are not captured in these data sets. This possib- ility is similar to the noted limitations of epidemiological studies conducted on members of the CAF that were aimed at determining the prevalence and incidence rates of different mental health issues including suicide (Roland-Harris 2019), where the restriction of only administering surveys to current-serving members without medical employment limitations means that those who are currently on sick-leave or had been recently released from service were not counted, leading to numbers that were acknowledged as being potentially artificially lower than the actual epidemiological rates.

6. Initiatives in the U.S. military that tackle the problem of sexual misconduct include a focus on increasing willingness and effectiveness of members to intervene in situations where sexual misconduct is or has occurred, ranging from direct intercession to active reporting and post-trauma support. The intent is to build upon beneficial elements of unit cohesion and camaraderie to create supportive and safe environments, ultimately leading to widespread culture change. This concept of promoting and encouraging bystander intervention does seem to have been adopted by the Canadian Armed Forces as part of Operation HONOUR (for more details on the U.S. initiatives, see Gedney et al. 2018; Holland \& Cipriano 2019; Holland et al. 2016; and Skopp et al. 2020).

7. The basic conceptual framework of these three archetypes was initially developed by the author while looking at how masculinity was implicated in the perpetuation of stigmatizing behaviour and attitudes towards military members and veterans with post-traumatic stress disorder (Callaghan 2014, 2018), and has been found useful in understanding a wide variety of topics and contexts encountered during the course of the doctoral research that this article is derived from. This conceptual framework was presented by the author at CIMVHR Forum 2019 (Callaghan 2019).

8. The concept of the moral injury is somewhat new and is the topic of much discussion in psychological and psychiatric circles. Where research on post-trau- 
matic stress disorder has focused primarily on fear-responses, the concept of the moral injury captures other psychological and social responses to trauma, particularly trust and betrayal, shame and guilt (for an introduction to this concept, see Currier et al. 2015; de Graaf et al. 2015; Drescher et al. 2011; Holliday and Monteith 2019; Litz et al. 2009; and Shay 2014). 


\section{References}

Brewster, Murray. 2019. "B.C. Says It Won't Waive Claim in \$900M Military Sexual Assault Settlement." CBC News. September 20. https://www.cbc.ca/news/ politics/sexual-assault-canadian-forces-900-millionsettlement-1.5291978.

Burczycka, Marta. 2019. Sexual Misconduct in the Canadian Armed Forces Primary Reserves, 2018.

Statistics Canada. https://www.canada.ca/en/ department-national-defence/services/benefits-military/ conflict-misconduct/operation-honour/research-dataanalysis.html.

Callaghan, Walter. 2014. "MAN UP! MAN DOWN!: Military Masculinity, Stigma, and Post-Traumatic Stress Disorder." MA thesis, Department of Anthropology, University of Toronto.

Callaghan, Walter. 2018. "What's Sex Got To Do With It? Social Imaginations of Military Masculinity and its Implications in Veteran Health Research." Canadian Anthropology Society Annual Conference. Santiago de Cuba.

Callaghan, Walter. 2019. "Allyship, Wilful Blindness and Toxic Masculinity: Veteran Responses to \#MeToo and Operation HONOUR." Canadian Institute for Military and Veteran Health Research Forum 2019. Ottawa-Gatineau.

Chapman, Krystel, and Maya Eichler. 2014. "Engendering Two Solitudes? Media Representaitons of Women in Combat in Quebec and the Rest Of Canada." International Journal: Canada's Journal of Global Policy Analysis 69 (4): 594-611.

Cotter, Adam. 2016. Sexual Misconduct in the Canadian Armed Forces. Statistics Canada. https:// www150.statcan.gc.ca/n1/pub/85-603-x/85-603x2016001-eng.htm.

Cotter, Adam. 2019. Sexual Misconduct in the Canadian Armed Forces Regular Force, 2018. Statistics Canada. https://www150.statcan.gc.ca/n1/pub/85603-x/85-603-x2019002-eng.htm.
Currier, Joseph M., Jason M. Holland, and Jesse Malott. 2015. "Moral Injury, Meaning Making, and Mental Health in Returning Veterans." Journal of Clinical Psychology 71 (3): 229-240.

Davis, Karen D. 2020. "Negotiating Gender Inclusion." In Strengthening the Canadian Armed Forces through Diversity and Inclusion, by Alistair D. Edgar, Rupinder Mangat, and Bessma Momani, 36-51. Toronto: University of Toronto Press.

Davis, Karen D. 2009. "Sex, Gender and Cultural Intelligence in the Canadian Forces." Commonwealth \& Comparative Politics 47 (4): 430-455.

de Graaf, Miriam C., Michelle Schut, Desiree E. M. Verweij, Eric Vermetten, and Ellen Giebels. 2015. "Emotional Reactions and Moral Judgement: The Effects of Morally Challenging Interactions in Military Operations." Ethics \& Behavior 26 (1): 14-31.

Department of National Defence. 2019. The Operation Honour Manual: A Comprehensive Guide to Information and Resources on Sexual Misconduct. Ottawa: Department of National Defence. https:// www.canada.ca/content/dam/dnd-mdn/documents/ reports/ 2019/20190719_OPERATION\%20HONOUR\%20 MANUAL_EN.PDF.

Deschamps, Marie. 2015. External Review into Sexual Misconduct and Sexual Harassment in the Canadian Armed Forces. Department of National Defence. http:// www.forces.gc.ca/en/caf-community-support-services/ external-review-sexual-mh-2015/summary.page.

Drescher, Kent D., David W. Foy, Caroline Kelly, Anna Leshner, Kerrie Schultz, and Brett T. Litz. 2011. "An Exploration of the Viability and Usefulness of the Construct of Moral Injury in War Veterans."

Traumatology 17 (1): 8-13.

Dursun, Sanela. 2019. "The Prevalence of Sexual Misconduct in the Military." Canadian Institute for Military and Veteran Health Research Forum 2019. Ottawa-Gatineau. 
Eichler, Maya. 2016. "Learning from the Deschamps Report: Why Military and Veteran Researchers Ought to Pay Attention to Gender." Journal of Military, Veteran and Family Health 2 (1): 5-8.

Eichler, Maya. 2013. "Women and Combat in Canada: Continuing Tensions Between 'Difference' And 'Equality.'" Critical Studies on Security 1 (2): $257-$ 259.

Foucault, Michel. 1975. Discipline and Punish: The Birth of the Prison. London: Penguin Books.

Gedney, Christine R., David S. Wood, Brad Lundahl, and Robert P. Butters. 2018. "Sexual Assault Prevention Efforts in the U.S. Air Force: A Systematic Review and Content Analysis." Journal of Interpersonal Violence 33 (3): 421-441.

Goffman, Erving. 1961. Asylums: Essays on the Social Situation of Mental Patients and Other Inmates.

London: Penguin Books.

Holland, Kathryn J., and Allison E. Cipriano. 2019. "Bystander Response to Sexual Assault Disclosures in the U.S. Military: Encouraging Survivors to Use Formal Resources." American Journal of Community Psychology 64 (1-2): 203-218.

Holland, Kathryn J., Verónica C. Rabelo, and Lilia M. Cortina. 2016. "See Something, Do Something: Predicting Sexual Assault Bystander Intentions in the Military." American Journal of Community Psychology 58 (1-2): 3-15.

Holliday, Ryan, and Lindsey L. Monteith. 2019. "Seeking Help for the Health Sequelae of Military Sexual Trauma: A Theory-Driven Model of the Role of Institutional Betrayal." Journal of Trauma \& Dissociation 20 (3): 340-356.

Kocum, Lucie, Kate Calnan, Danielle Mercer, and Taylor Oakie. 2017. Sexual Misconduct: Leadership and Implicit Bias Literature Review. Ottawa: Defence Research and Development Canada.
LeBlanc, Manon M. 2019. "Sexual Misconduct in the Canadian Armed Forces Training Environment." Canadian Institute for Military and Veteran Health Research Forum 2019. Ottawa-Gatineau.

LeBlanc, Manon M., Lesleigh E. Pullman, and Zhigang Wang. 2019. Survey on Sexual Misconduct in the Canadian Armed Forces: Basic Military Officer Qualification Administration. Ottawa: Defence Research and Development Canada.

LeBlanc, Manon M., Lesleigh E. Pullman, and Zhigang Wang. 2018. Survey on Sexual Misconduct in the Canadian Armed Forces: Basic Military Qualification Administration. Ottawa: Defence Research and Development Canada.

Litz, Brett T., Nathan Stein, Eileen Delaney, Leslie Lebowitz, William P. Nash, Caroline Silva, and Shira Maguen. 2009. "Moral Injury and Moral Repair in War Veterans." Clinical Psychology Review 29 (8): 695706.

McCristall, Philip, and Katherine Baggaley. 2019. "The Progressions of a Gendered Military: A Theoretical Examination of Gender Inequality in the Canadian Military." Journal of Military, Veteran and Family Health 5 (1): 119-126.

Okros, Alan, and Denise Scott. 2015. "Gender Identity in the Canadian Forces: A Review of Possible Impacts on Operational Effectiveness." Armed Forces \& Society 41 (2): 243-256.

Rolland-Harris, Elisabeth W. 2019. "More Than Just Counting Deaths: The Evolution of Suicide Surveillance in the Canadian Armed Forces." Military Medicine 184 (Supplement 1): 37-42.

Shay, Jonathan. 2014. "Moral Injury." Psychoanalytic Psychology 31 (2): 182-191.

Skopp, Nancy A., Hannah Roggenkamp, Timothy V. Hoyt, Heath M. Major, and Tammy J. Williams. 2020. "Army Sexual Harassment/Sexual Assault Response \& Prevention Program (SHARP) Tiger 
Team: A Model to Inform Prevention." Military

Behavioral Health 8 (1): 64-73.

Taber, Nancy. 2018. "After Deschamps: Men, Masculinities, and the Canadian Armed Forces." Journal of Military, Veteran and Family Health 4 (1): 100-107.

Taber, Nancy. 2020. "The Canadian Armed Forces: Battling Between Operation HONOUR and Operation Hop On Her." Critical Military Studies 6 (1): $19-40$.

Tasker, John Paul. 2018. "Ottawa Moves to Settle Sexual Misconduct Class Action Lawsuits Against Canadian Forces." CBC News. February 23. https:// www.cbc.ca/news/politics/class-action-lawsuits-sexualmisconduct-armed-forces- 1.4548968.

Tunney, Catherine. 2019. "Ottawa Sets Aside \$900M to Settle Sexual Misconduct Lawsuits Against Canadian Armed Forces." CBC News. July 18. https:// www.cbc.ca/news/politics/military-sexual-misconductsettlement-1.5216307.

Young, Lauren M., and Margaret M. Nauta. 2013. "Sexism as a Predictor of Attitudes Toward Women in the Military and in Combat." Military Psychology 25 (2): 166-171. 